\title{
Advanced Assistive Technologies for Elderly People: A Psychological Perspective on Seniors' Needs and Preferences (part A)
}

\author{
Alda Troncone ${ }^{1}$, Terry Amorese ${ }^{1}$, Marialucia Cuciniello ${ }^{1}$, \\ Raffaele Saturno $^{2}$, Luca Pugliese ${ }^{2}$, Gennaro Cordasco ${ }^{1}$, Carl \\ Vogel $^{3}$ and Anna Esposito ${ }^{1,2}$
}

\footnotetext{
${ }^{1}$ Department of Psychology, University of Campania "Luigi Vanvitelli”, Viale Ellittico 31, 81100 Caserta, Italy, alda.troncone@unicampania.it, terry.amorese@unicampania.it, marialucia.cuciniello@unicampania.it, gennaro.cordasco@unicampania.it

${ }^{2}$ International Institute for Advanced Scientific Studies (IIASS), Via G. Pellegrino 19, 84019 Vietri sul Mare, Salerno, Italy, 1.pugliese@ iiassvietri.it, raffaele.saturno@gmail.com, iiass.annaesp@tin.it

${ }^{3}$ School of Computer Science, and Statistics, Trinity College Dublin, Ireland, vogel@tcd.ie
}

\footnotetext{
Abstract: This paper provides an overview of the literature concerning Seniors' psychological perspective in exploiting assistive robots and the embodied conversational agents. The main theoretical models devoted to assess user's technology acceptance are briefly reviewed along with a description of the main factors empirically found to be positively/negatively associated with Seniors' acceptance level. Special attention is reserved to barriers generated by Seniors' representations of social assistive technologies, such as, a stigma or threat to their autonomy, infantilization, privacy interferences, fear of dehumanization and isolation.
}

Keywords: older user; assistive technology; robot; virtual agent; acceptance; preferences

\section{Introduction}

According to the United Nations, the number of people ages 65 and older will reach 2.1 billion by 2050 [1]. Luckily progress made in medicine and health care will help keep these Seniors healthy and in good shape mentally, even though physiological declines, such as, vision impairment, short-term memory problems and fine-motor deficits remain unavoidable. Depending on personal tendencies to react positively or negatively to life events and the severity of such impairments, 
Seniors may react by isolating themselves and limiting relationships with friends and relatives. However, social isolation is associated with reduced well-being and depression [2,3] and increased mortality [4]. Interventions are needed to prevent these negative consequences and social isolation itself.

One possibility consists of exploiting intelligent and socially believable ICT (Information Communication Technology) interfaces that support Seniors in living autonomously, simplifying their management of daily tasks and lightening workloads for caregivers. According to Shepherd [5]: "The Digital Era is characterized by technology which increases the speed and breadth of knowledge turnover .... [and] ... has changed the way we live and work and ... healthcare relationship." (pp. 1-3). Therefore, the development of the Digital Era implies that it's possible to use technology such as robots, and virtual agents, to help those who require assistance for daily life activities.

However, little is known about Seniors' interests in and willingness to interact with advanced assistive technologies in order to meet their needs. There is a general agreement that the successful incorporation of assistive social technologies in everyday life depends mainly on how the users perceive and accept them [6]. Robots and virtual agents may have to be adapted to meet users' specific needs and even personalized according to his/her likes and dislikes [7].

This paper reviews the literature on advanced assistive technologies aiming to improve the lives of older people and increase their well-being. The focus is on assistive robots and embodied conversational agents, in order to provide a full description and understanding of Seniors' psychological perspectives toward using such assistive technologies. The main theoretical models on user's technology acceptance, are reviewed and described and the main factors found to be positively or negatively associated with older users' acceptance are highlighted.

\section{Understanding Seniors' Psychological Perspectives: Acceptance and Associated Factors}

For people who are older, accepting new technology (i.e., the extent they are willing to incorporate it into their lives) "is an adaptive negotiation between the improvements provided by the offered resource and the struggles required to allocate it into their personal environment" [8, p. 2] [9]. It is necessary to consider the functionalities offered, of course, but other aspects are also urgent to analyze: the emotions the device may arouse, the cognitive effort required for its effective use, the engagement it produces, and the associated costs of having it. The information system (IS) and information technology (IT) literature describe several technology-acceptance models, most of them conceptualized for adult users. 


\subsection{Main Acceptance Models}

The existing acceptance models have been mostly based on theories in psychology and sociology, and despite differences in complexity and content, they were all employed with the goal of understanding, explaining and predicting factors influencing users' acceptance and willingness to use certain technologies [10,11].

The Technology Acceptance Model (TAM) [12] was developed in order to describe and comprehend potential users' expectations regarding information technology. The TAM highlights two variables influencing acceptance: (i) perceived usefulness, defined as the degree to which an individual believes that using a particular system will enhance his/her performance and (ii) perceived ease of use, defined as the degree to which an individual believes that using a particular system will require little or no effort $[12,13]$. According to this model, the degree of acceptance of a technological device is a directly connected to the efforts needed to use it for practical purposes and the individual gains derived from its use in facilitating the accomplishment of a given task. The TAM model has been applied to many different categories of technological devices and has collected strong empirical support $[14,15]$, thanks to its adaptability to a variety of domains.

However, TAM lacked several important psychological variables. To correct this, the model was extended as TAM2 in 2000 [14] with the addition of two theoretical constructs, namely social influence and cognitive instrumental processes, which affect the perceived utility of a technological device and the intention to use it. The social influence processes are conceptualized as subjective norms (i.e., the individual perception that friends and relatives think that the person should or should not adopt the behavior in question), willingness, and compliance with others' opinions (i.e., the extent to which users perceive that their adoption decision is made willingly and is not mandatory), image, and social influence (i.e., the individual perception that adopting an innovative tool is a way to enhance his or her social status) [14].

The cognitive instrumental processes are theorized starting from the assumption that people derive their judgments of perceived usefulness by considering a system's functional usefulness in relation to their needs to complete a particular task. In other words, people assess cognitively how important work goals are consequence of performing the work by using the system, and develop opinions regarding its perceived utility. In this context, four cognitive instrumental determinants are identified:

- Relevance for the task - Does the user perceive that the system in question applies to his/her task? To what degree does it apply?

- Level of quality - Does the system perform adequately to complete the identified task? 
- Demonstrability - Are the system's results tangible?

- Perceived ease of use

Essentially the TAM2 model accounted of theoretical mechanisms by which subjective norm can influence intentions to use a given system indirectly through the user's perceived usefulness. In particular, the model considered effects of how the user's perception that a significant referent utilizes the system leads herself to use it and how this perception changes during her own experience. It was hypothesized that the effects of the social influence weakened [14].

The extent to which the system's social skills and physical appearance influence user's acceptance were, however, neglected both in TAM and TAM2. Indeed, the user's expectations of the social abilities and semblances of such robot/agent systems play a crucial role in their acceptance [10] and were considered the premise for developing further theoretical models to predict user acceptance.

The Unified Theory of Acceptance and Use of Technology (UTAUT) [15] was formulated as the result of a review and synthesis of eight theories/models of technology use. These include Fishbein and Ajzen's theory of reasoned action [16]; Davis's technology acceptance model [12, 15]; the motivational model [17]; the theory of planned behavior [18]; a model that integrates the technology acceptance model and the theory of planned behavior $[12,18]$; the model of personal computer utilization [19]; the innovation diffusion theory by Rogers et al. [20]; and the Bandura's social cognitive theory [21].

In the UTAUT model, four well-defined constructs are believed to have a significant role as direct determinants of user's acceptance and usage behavior of a given technology. These include user's expectation of performance (the degree to which the individual believes that using that particular system will result in gains in job performance); effort expectancy (the degree of system's easiness of use the individual perceives); social influence (the degree to which one perceives that her family members and friends believe she should use the system); facilitating conditions (the degree to which the potential user believes to be supported by organizational and technical infrastructures for using the system). In particular, the model posits that social influence, performance expectations, and effort expectations will determine one's behavioral intentions to utilize a technology, while behavioral intentions and facilitating conditions influence the degree of usage. Furthermore, UTAUT identified experience, willingness to use voluntarily, sex and age as moderate influencing factors in using a given technological system [15].

The UTAUT2 model extended UTAUT to a consumer context. To this aim, hedonic motivations (e.g., pleasure of using the technology), cost value (the cognitive trade-off between perceived benefits and expenses related to its use), and habits (the degree to which one engages in a behavior automatically thanks to learning) are integrated into the original model, as further determinants theorized 
to influence user's intentions and use behavior [11]. Similarly, individual differences (i.e., sex, age, user experience) have been confirmed as moderating the effects of these constructs on behavioral intentions and use of technology.

The Almere Model was proposed by Heerink and colleagues [22] and inspired by UTAUT. It addresses user acceptance of assistive technology, in particular the use of assistive "social" robots by older people. The model was developed starting with the assumption that traditional models of technology acceptance fail to consider variables related to social interaction with robots and were developed without considering older people as potential users [22, 23], as well as validated in workplace settings [24].

The Almere Model identified a combination of theoretical constructs as significant and potential determinants of the intent to utilize new technologies. These include anxiety, attitude toward using technology, facilitating conditions, social influences (from the UTAUT), and perceived usefulness and easiness of use (from the TAM). To these, the Almere Model added the constructs of perceived enjoyment, perceived sociability, and social presence (considered worth social robots), in addition to perceived adaptability, which is appropriate to account for when older people are involved [25]. In particular, perceived adaptability turned out to be specifically applicable to vulnerable people such as elders since they want a system to help them only when they need and is designed to adapt to their changing needs.

An assessment of the Almere Model showed that "perceived usefulness" and "attitude" are the system features that most significantly affect Seniors' intentions to use a robot. Age, sex, voluntariness, educational level and computer experience proved to be moderating factors in determining their acceptance $[22,26]$.

The Technology-to-Performance Chain Model (TPC) [27] affirms that the adoption of technology is a consequence of its specific utility and the ability/capability of the technology to align with the tasks it is expected to support (i.e., task-technology fit). The model stresses the importance of an effective match between a technology's function and tasks the user wants to perform for gaining a performance impact from information technology.

The TPC model considers as factors affecting technology adoption: task's characteristics (the activities the individual needs to perform to complete the task), features of the technology (the technological tools the individual uses to perform the task), individual characteristics (competence, motivation, and experience of the people using technologies in order to obtain assistance in performing tasks); task-technology fit (the level of assistance given by the technology in helping the individual to complete a set of tasks, namely the correspondence between task requirements, person's abilities, and technology's functionality); utilization (employing the technology to perform a task); and performance impact (individual's accomplishment of a set of tasks) [10]. 
Beliefs about the consequences of use, affect toward use, social norms, and habitfacilitating conditions are considered precursors of the technology utilization. The feedback the individual acquires when using technology and her performance are identified as additional aspects influencing a person's decision about using the system again [27].

The Model of Acceptance of Technology in Households (MATH) [28, 29], using the theory of planned behavior [18] as its theoretical framework, was developed to understand factors affecting the domestic adoption of a technology (e.g., buying and using a personal computer). The model identified three classes of constructs:

- Attitudinal beliefs (conceptualized as utilitarian outcomes) - These beliefs are related to personal utility, usefulness for children, and work-related usage, as well as to hedonic outcomes (how much enjoyment is derived, for using a personal computer) and social outcomes (involving any potential increase in prestige as a result of buying a personal computer for home use).

- Normative beliefs - Related to the influence that family members, friends, workplace colleagues and other sources, may have on the technology adoption.

- Control beliefs - Internal or external depending on whether they relate to personal abilities (such as, concerns about obsolescence due to the rapid technology advances, apprehension related to one's beliefs regarding the skills and knowledge needed to use a personal computer, perceived easiness of use) or environmental factors (such as decreasing prices inhibiting the adoption of personal computers).

Brown and Venkatesh [28] proposed a theoretical extension of the MATH model integrating as demographic characteristics age, marital status, and child's age, that can change throughout one's lifespan and are considered to play moderating roles in the adoption of a technology.

To predict long-term engagement with a social agent, of significant interest is the attempt of Bickmore et al. [30] to exploit concepts proposed in the investment model of personal relationships for understanding the main processes involved in the maintenance of a relationship with an agent. The investment model, which is supported by empirical evidence $[31,32]$ was developed to explain engagement and commitment to close relationships.

According to the investment model, dependence upon and long-term orientation toward a relationship increases as a consequence of specific factors such as higher satisfaction, lower perceived quality of available alternatives, and greater investment size.

In line with this theory, Bickmore et al. [30] argued that individuals feel committed to a social agent because (1) they feel satisfied since the relationship 
provides rewards and does not involve significant costs (the user perceives that there are advantages related to interacting with the agent, e.g., they receive entertainment and/or useful information); (2) they have invested important resources in the relationship (the user view the system as an investment), and (3) their beliefs to have few available alternatives to their relationships. These factors all contribute to the user's commitment to a long-term relationship with the agent as well as to increase the likelihood of using the system [30].

\subsection{Main Factors Found to be Positively/Negatively Associated with Senior's Acceptance of Social Agents and Robots}

Literature examining acceptance of robots and social agents by Seniors has empirically supported the roles of most of the factors identified by the abovementioned acceptance models in influencing and moderating user acceptance.

However, beyond such formalized theoretical models, several further variables, often grouped by specific categorizations, were proposed as being associated with Seniors' acceptance.

De Graaf et al. [6] identified five main factors that may be considered to positively or negatively affect the elders' willingness to use and entrust a relationship with social agents and robots in the domestic sphere. Utilitarian factors, exemplified as accessibility and usability (the easier to use people perceive the device, the higher will be their level of acceptance), practical benefits (e.g., facilitating care delivery, enhancing personal safety in one's home, being a source for general information and health improvement), adaptability to the user's needs. Hedonic factors such as enjoyment related to use, attractiveness (size, physical appearance, anthropomorphism, etc.), and social intelligence (related to the robot/agent's ability to perform social behaviors, e.g., demonstrating traits associated with caring, intelligence, empathy, human-like communicative capacities, and companionship). Context of use factors such as social pressures, status gain, trust, privacy, previous experience, prior expectations, perceived behavioral control in relation to the data being recorded and stored. Situational factors, such as, the circumstances and the time of the day under which interactions with the agent/robot took place (influencing participants' experiences), the location, the presence of others in the house, the user's mood at the time of the interaction). User characteristics factors a such as age, sex, general level of interest in technology, and type of household. All of these factors will contribute to the domestication of the system (robot/agent), i.e. the long-term user acceptance of the assistive technology. Domestication requires an initial acquaintance of the system's functions and interactive behaviors, the incorporation of it into user's daily life, continued use of it, and the generation of ideas for future improvements. According to De Graaf et al. [6] hedonic rather pragmatic motivations appear to have impact more on the elders' acceptance of social assistive devices in their homes. 
The roles of key moderating factors such as age and other sociodemographic variables, previous experience with technology, and user's representation of assistive technology on long-term acceptance are examined in-depth in the following section.

\subsubsection{Age and other Sociodemographic Factors}

The impact of user's age on the credibility and reliability of assistive social technologies is controversial and, despite its possibility of moderating the influence of all the factors considered as affecting user acceptance, age has received scant attention by the related literature [15].

In this context controversial results have been highlighted. A portion of the current literature attributed to Seniors the following characteristics:

- Being less willing to use assistive technology, with positive attitude decreasing as age increases [26, 33-36]

- Being suspicious of new technology (in contrast to younger people, who are more confident); having reservations about using robots/agents seen as futuristic advanced technologies that can be difficult to master, and potentially will produce changes in the socio-physical aspects of their home environment [33, 35, 37-39]

- Being reluctant and even opposed to technological advances accompanied by their being less technologically literate; having an aversion toward using such devices because incompatible with their "generational habitus" [38, 40]

- Fearing the use of robots/agents because of their not-knowing and notmastering some technologies although some may have positive attitudes toward service robots to the extent the proposed assistive technology function without the user needing help from others or a large amount of training) [39]

- Being less inclined than younger people to adopt trial and error strategies when difficulties arise in operating the technology, and consequently seeking help of experts and feeling inappropriate themselves $[9,33,35$, 38]

On the other hand, other studies found no significant differences in regard to age and attitudes toward technology [41] and noted that one's chronological age becomes less important than his or her need. That is, when users who are older have specific needs that a particular technological device can help them meet, their level of acceptance increases and negative effects related to age decrease and lose relevance [35, 38, 42, 43]. Conversely and in agreement with the TAM framework, if the elderly person fails to experience the assistive robot/agent as helpful or useful, is less likely to agree to its presence in the home [41]. 
Regarding technology acceptance and gender, with respect to men, women have been described as:

- Less likely than men to accept and use assistive technologies; men were found to have a more accepting attitude about robotic technology and its use $[24,34,35,44-46]$

- Expecting that learning to use assistive technologies is more demanding [47]

- Being more skeptical and afraid of becoming dependent upon the assistive technology $[35,38]$

- Preferring a greater distance between themselves and the robotic device and uncertain about talking to a nonhuman device [35, 38]

- Less inclined than men to anthropomorphize because they do not perceive the robot/agent as an autonomous person [35, 48]

- Being more conscientious in regard to monitoring their own health with the help of assistive technology [35, 36]

- Being interested in specific features of the robot [33, 49]

Conversely, other evidence described women as more interested than men in interacting with a robot/agent, viewing the robot as a human male, and having a more positive attitude toward establishing a relationship with a virtual companion $[33,50-52]$. It was also found that some gender differences can be misleading without reference to age. [15].

In regard to educational level, people with lower levels of education have been described as less confident about their ability to master a novel device and as reporting greater resistance and negativity toward technology than those who had finished their high school education and those who had earned a college degree $[9$, 38]. Similarly, for older adults, more education was linked to greater acceptance in regard to using technology to solve everyday problems but with less openness in perceiving a robot/agent as a social entity $[9,26,35]$. However, other evidence does not support moderating effects of the education level on older users' technology acceptance [53].

\subsubsection{The Role of Experience with Technology}

Direct experience or lack of familiarity with technology were described as playing relevant roles in influencing user attitude and preference regarding an assistive device [33, 35, 54, 55]. Being familiar with various forms of technology was found to affect users' attitudes about these systems and increase their adoption of technology no matter of the age [26, 56-58]. 
Furthermore, users prior experience in using technology, is a deciding factor in their acceptance of new technological devices. This finding is considered as moderating the role of age and other sociodemographic variables [35]. In other words, it has been argued that those who are younger may be more likely than older individuals to accept robots/virtual agents since they are more familiar with them [35]. The moderating effect of having experience using technology hold true regarding gender and educational level as males usually have greater experiences using technology than females do, and similarly, those with less education seem to have less experience with technology [35]. Some research has confirmed that males who have had more experience with computers perceive robots as easy to use [26].

However, it should be noted that other evidence described no significant associations between user's level of acceptance and willingness to use assistive technology and gender, education, age, or participants' prior experience using technology, either in using a virtual agent [23] or using and interacting with assistive robotic technology [57, 59]. Such discrepancies among several studies demonstrates the complexity to isolate from these robot/agent human interactions the effects of sociodemographic and behavioral factors on user acceptance [35].

\subsection{The Barrier of User's Representation of Social Assistive Technology}

A critical role in user's acceptance is acknowledged to be the user's technology device representation, which can serve as a barrier to the use of a new device in several ways.

\subsubsection{Stigma, Threat to Autonomy and Infantilization}

A significant impediment to user acceptance is the possibility to stigmatize the use of robots/agents [40]. This stigma derive from the belief of some Seniors that the needing to be assisted by a robot/agent can be interpreted as an emblematic aging, characterized by loneliness, and mental and/or physical declines [40, 60, 61]. This perception leads older individuals to refuse the use of social assistive technology striving to appear in good shape, active, and independent, i.e., not yet in need of an assistive device [35, 60, 62]. For these Seniors assistive technologies were considered to assist people handicapped, dependent on others, frail or ill, or living alone without family or friends to assist them [40].

In addition, some Seniors perceive assistive technology devices as threatening their autonomy and self-image [63]. This population fears that using assistive technology potentially reduces their current skills and abilities and induces dependence on machines [64]. Therefore these Seniors felt that being treated condescendingly by a machine which limits their executive control in relation to 
daily as well as longer-term decisions diminishes or undermines their autonomy and result in an infantilization [63, 65]. As an example, some Seniors feel disheartening and encouraged to adopt regressive behaviors when proposed to use dolls or stuffed toys, regardless of their therapeutic potential $[65,66]$.

Additionally, there is evidence that Seniors prefer to keep doing things on their own, and manage tasks difficult for them using adaptation and/or compensatory strategies rather than depending on something that might prevent them from making an effort [40]. Even in the case of cognitive impairment, this attitude was found to prevent some participants from considering themselves as potential users of assistive technologies [67].

\subsubsection{Control and Privacy}

Accepting assistive technology is highly correlated with issues of control and privacy.

The need and feeling of being able to control the device and predict its behavior has been described as a variable playing a crucial role in user acceptance [61, 68].

Seniors described a virtual companion as being acceptable to them if it serves proactively as an assistant whose actions can be set by a timer or initiated by the user. To them the assistant must be unobtrusive and able to be deactivated when the user chose to do so $[6,23,69]$. Seniors wanted to be able to control the companion and accept to integrate it into their environment if it behaves reactively rather than proactively $[23,62]$.

Another problem is related to the user's privacy because when a system is designed to assist the user in performing daily activities, the use of cameras or sensors is essential, but at the same time, the user's privacy should be respected $[10,66]$. Specifically, older adults were found to express concerns about the use of cameras and the possibility that their interactions with the assistive device might be recorded for others to view [23]. To this aim, Seniors expressed concerns about feeling watched and invaded in their privacy $[40,61]$. For these reasons, several authors suggested that video cameras should be able to observe only a predefined and restricted area and sensors should be activated only by the user [62].

In addition, it is crucial for Seniors to be able to access the video recordings delete all or parts of the data at their will $[6,23]$.

\subsubsection{Fear of Dehumanization and Isolation}

Seniors fear the use of assistive devices if such devices are intended to replace human presence and reduce human social contacts thereby further isolating them from family and friends $[37,40,58,66,69,70]$. Similarly, the lack of authenticity of a companion device could also explain the unwillingness of elderly persons to adopt assistive technologies [67]. In particular, Seniors were found to express 
reluctance about using assistive devices that were perceived as having inauthentic expressions and offering artificial interactions [70]. As a result, even Seniors welldisposed to using robotic and virtual agent assistants, when asked to choose, expressed clear preferences for human assistance for specific tasks such as those related to personal care, taking medications, and leisure activities [71- 73].

Evidence suggested that the capacity of a virtual assistant to interpret a user's moods or emotions is negatively seen by Seniors which attributed these abilities uniquely to humans [23]. As consequences of these feelings, Seniors frequently expressed fears, regarding the dehumanization of our society, in terms of changing the fundamental role of humans, threatening the uniqueness of each person while caring of vulnerable people $[40,67,70]$.

\subsection{How to Assess a User's Attitude and Level of Acceptance}

Considering the many differences among older persons, any design for a successful assistive device, as well as which type of device is selected, can be determined only after an accurate assessment of the potential user's needs and preferences, as well as her daily living arrangements [74]. Several critics remarked that professionals involved in creating and producing assistive technological devices, neglect to solicit the input of their end users relying on subjective, biased, and skewed interpretation of the feelings and requirements of the target population thus having a negative impact on the device's design $[35,60]$.

Therefore, there is a critical need to survey elderly persons and accurately represent their requirements, expectations, and values in regard to emergent technologies aiming to assist them. Doing so can undoubtedly provide valuable information about how Seniors conceptualize these assistive devices and which design may be successfully adopted $[75,76]$. In order to understand beneficial functionalities and meeting Seniors daily needs in the application domain a combination of quantitative data-collection methods, direct observations, semistructured interviews, focus groups, were adopted [40].

Quantitative methods have produced several questionnaires and user-opinion measures to explore Seniors' perceptions, attitudes, and expectations about assistive devices.

The TAM measurement scale [12] measures two variables hypothesized to be determinants of technology usage, i.e., perceived usefulness (PU) and perceived ease of use (PEOU). These two constructs were each measured through 6 items exemplified in the form of statements expressing the respondent's likelihood to adopt a given behavior toward the assistive device being assessed. Each respondent's answer is measured by through two, 7-point Likert scales, one with likely-unlikely endpoint adjectives and the other, reversed in polarity, with improbable-probable endpoints. This questionnaire was adapted in one study to 
measure user acceptance of a robotic system by evaluating the PU and PEOU of different functionalities offered by the proposed robot [77].

The TAM2 measurement scale comprises 26 items measuring four constructs encompassed in the TAM2 model, namely intention to use ( 2 items), perceived usefulness (4 items), social influence (including subjective norms, 2 items), voluntariness (3 items), image ( 3 items), and instrumental cognitive processes (including job relevance, 2 items), output quality (2 items), results' demonstrability (4 items), and perceived easiness of use (4 items) [14]. All items were measured on a 7-point Likert scale, from $1=$ strongly disagree, $2=$ moderately disagree, $3=$ somewhat disagree, $4=$ neither disagree nor agree, 5 somewhat agree, $6=$ moderately agree, to $7=$ strongly agree.

The UTAUT questionnaire was based on 7 constructs: performance expectancy (4 items), effort expectancy (4 items), attitude toward using technology (4 items), social influence (4 items), facilitating conditions (4 items), self-efficacy (4 items), anxiety (4 items), and intention to use (3 items) [15].

All items were measured on a 5-point Likert scale, asking participants to indicate their level of agreement to statements from $1=$ strongly disagree, to $5=$ strongly agree.

The items were adapted by several authors, and the original 31 items were modified on the basis of the aims of their studies [15, 45, 46].

The subsequently extension UTAUT2, substituted for the constructs of anxiety attitude toward using technology and self-efficacy, the constructs of hedonic motivations (3 items), price values (3 items), and habits (4 items) which were considered more appropriate factors affecting technology acceptance. The final questionnaire was composed of a 29 items measured (except for the "use behavior" item, which was not specified) with a seven-point Likert scale, ranging from "strongly disagree" to "strongly agree" [11].

The above questionnaires and associated theories from which they developed do not account of users' ages and in particular do not consider either Seniors as end users, or assistive technologies such as robots and virtual assistants.

The Almere model aimed to assess users' acceptance of assistive social robots designed for elder-care environments [25]. The questionnaire was based on 13 constructs: anxiety, attitude towards technology, facilitating conditions, intention to use, perceived adaptiveness, perceived enjoyment, perceived ease of use, perceived sociability, perceived usefulness, social influence, social presence, trust and intention to use. So far, it is the only psychological scale that purports to assess users' perceptions of social robots in human-robot interactions specifically considering Seniors $[22,25]$. All the 41 items are measured on a 5-point Likerttype scale ranging from 1 to 5 (totally disagree, disagree, don't know, agree, totally agree). Higher scores indicate higher acceptance [25]. 
It should be noted that, while the final version of the questionnaire was being developed, questions concerning acceptance and relying upon the abovementioned constructs were adopted in several studies [24, 40]. In addition, modified versions of the original questionnaire referring to several of the constructs theorized in the Almere model were used to assess elderly users' acceptance of an assistive social-agent system $[61,78]$.

The Person-Robot Complex Interactive Scale (PRCIS) was proposed to investigate human - robot interactions; it considers human diversity as well as diversity among types of robotic systems [79, 80].

The PRCIS has four sections: two consider the instructor's evaluation and two target the participant's assessment. The two sections aiming to assess the instructor's overall evaluation of human-robot interactions, use a multiple-choice scale. This scale considers facets of participant's behaviors, from disruptive to interactive, overall verbal and nonverbal intensity of communication, engagement level, and prevailing mood. In particular, the instructor assesses the participant's individual communication style with the robotic device assessing parameters associated to the nonverbal interactions (including tactile and manipulative patterns), the participant's verbal responses (whether and to what degree she interacts with the robot using words or utterances), and emotional aspects of the participant's communicative interactions (positive or negative reactions to the robot's behavior).

The two sections involving the participant's evaluation of the robotic system consider participant's likes and dislikes of the robot interactional abilities, novelty of the experience, evaluation of the system's features, identified advantages and drawbacks of the system, and any prior experiences with this type of technology.

All of the PRCIS's subscales take into consideration negative and positive displays and measure behaviors using a 5-point Likert-type assessment. Moreover, the use of open-ended questions provides the opportunity to express feelings on the perceived pros and cons of the robotic system $[79,80]$.

The Robot Attitude Scale (RAS) comprises 12 dimensions designed to measure respondents' attitude toward robotic systems rated on a scale from 1 to 8 : safeness/danger of the robotic system, reliability/unreliability, friendliness/unfriendliness, simple/complicated, usefulness/uselessness, strong/fragile, interesting/boring, trustworthy/untrustworthy, advanced/basic, easy to use/difficult to use, and helpful/unhelpful). Lower scores represent morepositive perceptions [33, 59, 81].

The Negative Attitude Towards Robots Scale (NARS) [82, 83] was developed to assess respondents' general attitudes about robotic systems (before humanrobot interaction studies were conducted with the respondents). This scale has 14 items categorized as three subscales: negative attitude toward situations and interactions (6 items); negative attitude toward robots' social influence (5items); and negative attitude toward emotional interactions with robots (3 items) [78]. 
The Robot Anxiety Scale (RAS) [83, 84] was developed to determine and measure state-like anxiety that may be evoked by robots in real and imaginary human robot interaction situations. This scale comprises 11 items grouped into three subscales: anxiety toward communication capacity of robots (3 items); anxiety toward behavioral characteristics of robots (4 items); and anxiety toward discourse with robots 4 items).

The Perception to Humanoid Scale (PERNOD) comprises 33 items designed to measure people's impressions of a humanoid robot. This humanoid-oriented scale is based on five fundamental dimensions: familiarity, utility, motion, controllability, and toughness [85].

The Godspeed Questionnaire Series measures users' opinions and perceptions of a robot on 5 constructs: anthropomorphism (5 items), animation (6 items), likeability (6 items), perceived intelligence ( 5 items), and perceived safety (3 items). The items in the different categories were interleaved and a 5-point Likerttype scale was used [86].

The Robot Opinion Questionnaire was developed to evaluate Seniors' attitudinal acceptance of robots. It is a revision of the TAM technology-acceptance scale that is specific to robots. The questionnaire has 12 items measured by a 7-point Likerttype scale $(1=$ extremely unlikely, $4=$ neither unlikely nor likely, $7=$ extremely likely). Sample items include: "My interaction with a robot would be clear and understandable"; "I would find a robot useful in my daily life"; and "Using a robot would make my daily life easier" [72].

Several studies adopted measurement tools from social and clinical psychology in order to assess user-agent relationships. These scales are described below.

The Comfort from Companion Animals Scale is a 11-item questionnaire, designed to measure respondents' attachment to the comfort they perceive in reflection on from a pet robot exploited as companion [87]. This scale is generally used to evaluate people's close companionship with their pets. It was then considered useful also for measuring similar feelings toward virtual pets or petlike robots [88]. The level of agreement/disagreement toward the 11 items was measured on a 4-point Likert-type scale ranging from strongly agree (4 points) to strongly disagree (1 point).

The Lexington Attachment to Pets Scale (LAPS) [89] is a 23-item questionnaire originally designed for evaluating attachment to pets. The 23 items are grouped into three subscales (general attachment, people substitution, and animal rights/animal welfare) and was appropriately modified for evaluating people's attachment toward interactive robotic pets [90].

The Companion Animal Bonding Scale [91] is an 8-item behavioral scale evaluating child-animal interactions. It evaluates the acceptance of a robot an inhome companion by Seniors living independently at home (i.e., aging in place) [92]. 
The Working Alliance Inventory (WAI) is a questionnaire used in psychotherapy to assess the quality of a client-therapist relationship [93, 94]. It consists of 36-items exemplified into three constructs: a) bond, establishing the degree of liking and trust between the assistants and people in need (e.g., "My relationship with [name of virtual agent] is very important to me"); b) task, considering the degree of both helper and receiver in performing therapeutic tasks (e.g., "The things that [name of virtual agent] is asking me to do/ don't make sense"); and c) goal, assessing the extent the assistant and assisted person agree on the goals of the therapy (e.g., "[name of virtual agent] perceives accurately what my goals are"). The WAI items have been slightly modified in order to be appropriate for referring to a robotic device. For example, the statement "I understand (person) and she understands me" was modified as "I understand [name of virtual agent] and she understands me, at least in the best way she can." [95].

The Positive and Negative Affect Schedule (PANAS) was used to measure positive/negative emotions during a human-robot device interaction PANAS consists of 10 positive and 10 negative words related to emotions (e.g., enthusiastic, afraid, etc.) rated on a 5-point scale from "very slightly or not at all", to "very much". The respondent's rate the PANAS words in response to the question: How do you currently feel about using a health care robot? [59, 96]

A modified version of the Social Interaction Scale [97] was used to evaluate participants' ratings of their level of enjoyment while interacting with a robotic device. Specifically, participants were asked to indicate how much they enjoyed this interaction; how was it was smooth, natural, and relaxing; their desire to interact with the device again; the extent to which the interaction was forced, strained, or awkward; the extent to which they feel to control the interaction with the device; how intimate they perceived the interaction; the extent to which the interaction was satisfying, pleasant. [44, 97].

The dyadic interaction paradigm developed by Ickes et al. [98] to assess interactions between human dyads was adapted to collect users' (not necessarily older users) thoughts and feelings during interaction with a robotic device [96]. The frequencies, valence (positive or negative) and content of each thought and feelings were evaluated [99].

In addition, human acceptance of virtual agents and robots as well as user preferences, perceptions, opinions, levels of satisfaction, and perception of attractiveness and engagement with such agents have been also investigated using single or multi-item scales, questionnaires with multiple-choice and open-ended questions, and semi-structured interviews developed ad hoc according to the aims of the particular research $[6,10,23,30,39-41,59,64,67-72,93,95,100-113]$.

Similarly, focus group interviews or recordings of human-agent interactions were exploited as methods for exploring how users envision their interactions with 
robotic assistants or investigate opinions and expectations of older people about their appearance and functions $[23,61,62,67,68,70,81]$.

\section{Conclusions}

An accurate and personalized evaluation of Seniors' needs, psychological functioning and current life context is required to successfully incorporate assistive social technologies in Seniors' everyday life. Currently, there is no clear vision of which Seniors' expectations concerning robot characteristics and how to personalize/customize social assistive technology configurations, fits all possible application's scenarios [61]. Therefore, highly flexible systems need to be implemented. The complex interactions among sociodemographic, and cultural factors, such as personal experience with technology, preferences, robot's appearance, usefulness, costs and cognitive efforts for robot uses entail the demand of a deep and accurate analysis of each use case, in order to achieve Seniors' acceptance of such devices [35].

Particular attention should be devoted to the stigma derived from associating physical and cognitive declines, dependence on others, frailty and illness to the use of robots/agents, as well as, threatening their autonomy and self-image.

The major risk is infantilization and loss of dignity. Seniors fear that assistive devices limits their executive control and undermine their autonomy. To overcome these feelings, Sharkey [114] proposed the "capability approach." This approach allows for the identification of situation where robotic devices can potentially enhance Seniors' dignity by expanding their capabilities to autonomously handle daily activates and be engaged in social relationships. Therefore, any intelligent autonomous system that has been implemented to assist elders must be equipped with functionalities that do not mishandle their intelligence but supports their well-being. These functionalities must provide a sense of physical security, support different experiences, provide care for recreation activities and encourage sensory experiences, ideas and creativity [63, 114]. Similarly, appropriate countermeasures for data protection, security and privacy must be accounted for, to ensure Seniors' acceptance and incorporate such technologies into their home environments $[63,115]$.

\section{Acknowledgement}

The research leading to these results has received funding from the European Union Horizon 2020 research and innovation programme under grant agreement N. 769872 (EMPATHIC) and N. 823907 (MENHIR), from the project SIROBOTICS that received funding from Ministero dell'Istruzione, dell'Università, e della Ricerca (MIUR), PNR 2015-2020, Decreto Direttoriale 1735 July 13 2017, and from the project ANDROIDS that received funding from Università della Campania "Luigi Vanvitelli" inside the programme V:ALERE 2019, funded with D.R. 906 del 4/10/2019, prot. n. 157264, October 172019. 


\section{References}

[1] United Nations: Word population aging 2015, Report, New York 2015

[2] Philip, I. (2005) Ageing and health. Community Practitioner, 78, pp. 9-11

[3] Yin-Leng, T., and Paye, A. (2011) Designing with and for the elderly: An interactive digital social activity space addressing elderly loneliness and encouraging active ageing. In Proceedings IADS, International Conference ICT, Society and Human Beings, Rome, Italy, 2011 (pp. 27-43)

[4] Steptoe, A., Shankar, A., Demakakos, P., and Wardle, J. (2013) Social isolation, loneliness, and all-cause mortality in older men and women. Proceedings of the National Academy of Sciences of the United States of America, 2013 (Vol. 110, No. 15, pp. 5797-5801)

[5] Shepherd, J. (2004) What is the digital era? In G. Doukidis, N. Mylonopoulos, N. Pouloudi, editors, Social and Economic Transformation in the Digital Era. Idea Group Inc., Hershey, PA, USA, 2004 (pp. 1-8)

[6] De Graaf, M. M., Allouch, S. B., and Klamer, T. (2015) Sharing a life with Harvey: Exploring the acceptance of and relationship-building with a social robot. Computers in Human Behavior, 43, 1-14

[7] Tokunaga, S., Tamamizu, K., Saiki, S., Nakamura, M., and Yasuda, K. (2017) Virtual Care Giver: personalized smart elderly care. International Journal of Software Innovation (IJSI), 5(1), 30-43

[8] Esposito A., Amorese T., Cuciniello M., Esposito A. M., Troncone A., Torres M. I., Schlögl S., and Cordasco G. (2018) Seniors' acceptance of virtual humanoid agents. In Italian Forum of Ambient Assisted Living, Springer, Cham, 2018 (pp. 429-443)

[9] Giuliani, M. V., Scopelliti M., and Fornara, F. (2005) Elderly people at home: technological help in everyday activities. In Robot and Human Interactive Communication. ROMAN 2005 IEEE International Workshop, Aug 13-15, Nashville, TN, US, 2005 (365-370)

[10] Beer, J. M., and Takayama, L. (2011) Mobile remote presence systems for older adults: acceptance, benefits, and concerns. In Proceedings of the $6^{\text {th }}$ international conference on Human-robot interaction, Lausanne, $\mathrm{CH}$ (pp. 19-26)

[11] Venkatesh, V., Thong, J. Y., and Xu, X. (2012) Consumer acceptance and use of information technology: extending the unified theory of acceptance and use of technology. MIS Quarterly, 157-178

[12] Davis, F. D. (1989) Perceived usefulness, perceived ease of use, and user acceptance of information technology. MIS Quarterly, 13(3), 319-340 
[13] Surendran, P. (2012) Technology Acceptance Model: A Survey of Literature. International Journal of Business and Social Research, 2(4), $175-178$

[14] Venkatesh, V., and Davis, F. D. (2000) A theoretical extension of the technology acceptance model: Four longitudinal field studies. Management Science 46(2), 186-205

[15] Venkatesh, V., Morris, M. G., Davis, G. B., and Davis, F. D. (2003) User acceptance of information technology: Toward a unified view. MIS Quarterly, 425-478

[16] Fishbein, M., and Ajzen, I. (1975) Belief, attitude, intention and behavior: An introduction to theory and research. Reading, MA: Addison-Wesley

[17] Davis, F. D., Bagozzi, R. P., and Warshaw, P. R. (1992) Extrinsic and intrinsic motivation to use com- puters in the workplace. Journal of Applied Social Psychology, 22(14), 1111- 1132

[18] Ajzen, I. (1991) The Theory of Planned Behavior. Organizational Behavior and Human Decision Processes, 50(2), 179-211

[19] Thompson, R. L., Higgins, C. A., and Howell, J. M. (1991) Personal computing: Toward a conceptual model of utilization. MIS Quarterly 15(1), 124-143

[20] Rogers, E. (1995) Diffusion of Innovations. New York: Free Press

[21] Bandura, A. (1986) Social Foundations of Thought and Action: A Social Cognitive Theory. Prentice Hall, Englewood Cliffs, NJ

[22] Heerink, M., Kröse, B., Evers, V., and Wielinga, B. (2010) Assessing acceptance of assistive social agent technology by older adults: The Almere Model. International Journal of Social Robotics, 2(4), 361-375

[23] Tsiourti, C., Joly, E., Wings, C., Moussa, M. B., and Wac, K. (2014) Virtual assistive companions for older adults: qualitative field study and design implications. In Proceedings of the 8th International Conference on Pervasive Computing Technologies for Healthcare, Oldenburg. Brussels (Belgium): ICST, 2014 (pp. 57-64)

[24] Heerink, M., Ben, K., Evers, V., and Wielinga, B. (2008) The influence of social presence on acceptance of a companion robot by older people. Journal of Physical Agents 2, 33-40

[25] Heerink, M., Krose, B., Evers, V., and Wielinga, B. (2009 September) Measuring acceptance of an assistive social robot: a suggested toolkit. The $18^{\text {th }}$ IEEE International Symposium on Robot and Human Interactive Communication, Toyama, Japan, RO-MAN 2009 (pp. 528-533)

[26] Heerink, M. (2011) Exploring the influence of age, gender, education and computer experience on robot acceptance by older adults. In Proceedings of 
the $6^{\text {th }}$ ACM/IEEE International Conference on Human-Robot Interaction (HRI '11), Lausanne, Switzerland (pp. 147-148)

[27] Goodhue, D. L., and Thompson, R. L. (1995) Task-technology fit and individual performance. MIS Quarterly, 19(2), 213-236

[28] Brown, S. A., and Venkatesh, V. (2005) Model of adoption of technology in households: A baseline model test and extension incorporating household life cycle. MIS quarterly, 399-426

[29] Venkatesh, V., and Brown, S. A. (2001) A Longitudinal Investigation of Personal Computers in Homes: Adoption Determinants and Emerging Challenges. MIS Quarterly, 25(1), 71-102

[30] Bickmore, T., Schulman, D., and Yin, L. (2010) Maintaining engagement in long-term interventions with relational agents. Applied Artificial Intelligence, 24(6), 648-666

[31] Rusbult, C. E., and Buunk, B. P. (1993) Commitment processes in close relationships: An interdependence analysis. Journal of Social and Personal Relationships, 10(2), 175-204

[32] Rusbult, C. E., Drigotas, S. M., and Verette, J. (1994) The investment model: An interdependence analysis of commitment processes and relationship maintenance phenomena. In D. J. Canary \& L. Stafford, editors, Communication and relational maintenance, Academic Press, San Diego, CA, US, 1994 (pp. 115-139)

[33] Broadbent, E., Stafford, R., and MacDonald, B. (2009) Acceptance of healthcare robots for the older population: Review and future directions. International Journal of Social Robotics, 1(4), 319-330

[34] Arras K. O., and Cerqui, D. (2005) Do we want to share our lives and bodies with robots? A 2000 people survey. Technical Report, 0605-001, 141

[35] Flandorfer, P. (2012) Population ageing and socially assistive robots for elderly persons: the importance of sociodemographic factors for user acceptance. International Journal of Population Research. 2012, 1-13

[36] Kowalewski, S., Wilkowska, W., and Ziefle, M. (2010) Accounting for user diversity in the acceptance of medical assistive technologies. In Proceedings of the $3^{\text {rd }}$ International ICST Conference on Electronic Healthcare for the $21^{\text {st }}$ Century, Casablanca, Morocco, 2010 (pp. 175-183)

[37] Robinson, H., MacDonald, B., and Broadbent, E. (2014) The role of healthcare robots for older people at home: A review. International Journal of Social Robotics, 6(4), 575-591

[38] Scopelliti, M., Giuliani, M. V., and Fornara, F. (2005) Robots in a domestic setting: a psychological approach. Universal Access in the Information Society, 4(2), 2146-155 
[39] Xu, Q., Ng, J. S., Tan, O. Y., and Huang, Z. (2015) Needs and attitudes of Singaporeans towards home service robots: a multi-generational perspective. Universal Access in the Information Society, 14(4), 477-486

[40] Wu, Y. H., Wrobel, J., Cornuet, M., Kerhervé, H., Damnée, S., and Rigaud, A. S. (2014) Acceptance of an assistive robot in older adults: a mixedmethod study of human-robot interaction over a 1-month period in the Living Lab setting. Clinical interventions in Aging, 9, 801-811

[41] Ezer, N., Fisk, A., and Rogers, W. (2009) Attitudinal and intentional acceptance of domestic robots by younger and older adults. In C. Stephanidis, editor, Universal Access in Human-Computer Interaction Intelligent and Ubiquitous Interaction Environments, Berlin, Germany: Springer (Vol. 5615, pp. 39-48)

[42] McCreadie, C., and Tinker, A. (2005) The acceptability of assistive technology to older people. Ageing and Society, 25 (1), 91-110

[43] Mitzner, T. L., Boron, J. B., Fausset, C. B., Adams, A. E., Charness, N., Czaja, S. J., Dijkstra, Fisk, A. D., Rogers, W. A., and Sharif, J. (2010) Older adults talk technology: technology usage and attitudes, Computers in Human Behavior, 26(6), 1710-1721

[44] Kuo, I. H., Rabindran, J. M., Broadbent, E., Lee, Y. I., Kerse, N., Stafford, R. M. Q., and MacDonald, B. A. (2009), Age and gender factors in user acceptance of healthcare robots. In Proceedings of the $18^{\text {th }}$ IEEE International Symposium on Robot and Human Interactive, ROMAN '09, Toyama, Japan (pp. 214-219)

[45] Heerink, M., Kröse, B. J. A., Wielinga, B. J., and Evers, V. (2006a) Studying the acceptance of a robotic agent by elderly users. International Journal of Assistive Robotics and Mechatronics, 7(3), 33-43

[46] Heerink, M., Krose, B., Evers, V., and Wielinga, B. (2006b, September). The influence of a robot's social abilities on acceptance by elderly users. In The $15^{\text {th }}$ IEEE International Symposium on Robot and Human Interactive Communication, ROMAN, Hatfield, UK, 2006 (pp. 521-526)

[47] Venkatesh, V., and Morris, M. G. (2000) Why Don't Men Ever Stop to Ask For Directions? Gender, Social Influence, and Their Role in Technology Acceptance and Usage Behavior, MIS Quarterly, 24 (1), 115-139

[48] Schermerhorn, P., Scheutz, M., and Crowell, C. R. (2008 March) Robot social presence and gender: Do females view robots differently than males? In Proceedings of the $3^{\text {rd }}$ ACM/IEEE international conference on Human robot interaction, Amsterdam, Netherlands, 2008 (pp. 263-270)

[49] Taggart, W., Turkle, S., \& Kidd, C. D. (2005 July). An interactive robot in a nursing home: Preliminary remarks. In Towards social mechanisms of android science: A COGSCI workshop (pp. 56-61) 
[50] Machesney, D., Wexler, S. S., Chen, T., and Coppola, J. F. (2014 May) Gerontechnology Companion: Virtual pets for dementia patients. In Systems, Applications and Technology Conference (LISAT), IEEE, Long Island, 2014 (pp. 1-3)

[51] Shiabata, T., Wada, K., Ikeda, Y., and Sabanovic, S. (2009) Cross-cultural studies on subjective evaluation of a seal robot. Advanced Robotics, 23(4), 443-458

[52] Siino, R. M, and Hinds, P. J. (2005) Robots, gender \& sensemaking: Sex segregation's impact on workers making sense of a mobile autonomous robot. In Proceedings of the IEEE international conference on robotics and automation, Barcelona, 2005 (pp. 2773-2778)

[53] Derose J. J., Balaram, S. K., Ro, C., Swistel, D. G., Singh, V., Wilentz, J. R., Todd, G. J., and Ashton, R. C. (2005) Mid-term results and patient perceptions of robotically-assisted coronary artery bypass grafting. Interactive Cardiovascular and Thoracic Surgery, 4, 406-411

[54] Forlizzi, J. (2005) Robotic products to assist the aging population. Interactions, 12(2), 16-18

[55] Wada, K., and Shibata, T. (2007) Robot therapy in a care house: Change of relationship among the residents and seal robot during a 2-month long study. In: Proceedings of the $16^{\text {th }}$ IEEE international symposium on robot and human interactive communication RO-MAN, Jeju Island, Korea, 2007 (pp. 107-112)

[56] Sorri, L., and Leinonen, L. (2008) Technology that persuades the elderly. In H. Oinas-Kukkonen, P. Hasle, M. Harjumaa, K. Segerst ${ }^{\circ} a h l$, and P. Øhrstrøm, editors, Persuasive Technology, Berlin, Germany: Springer, (Vol. 5033, pp. 270-273

[57] Stafford, R. Q., MacDonald, B. A., Jayawardena, C., Wegner, D. M., and Broadbent, E. (2014) Does the robot have a mind? Mind perception and attitudes towards robots predict use of an eldercare robot. International journal of social robotics, 6(1), 17-32

[58] Young, J. E., Hawkins, R., Sharlin, E., and Igarashi, T. (2009) Toward acceptable domestic robots: Applying insights from social psychology. International Journal of Social Robotics, 1(1), 95-108

[59] Broadbent, E., Kuo, I. H., Lee, Y. I., Rabindran, J., Kerse, N., Stafford, R., \& MacDonald, B. A. (2010) Attitudes and reactions to a healthcare robot. Telemedicine and e-Health, 16(5), 608-613

[60] Neven, L. (2010) "But obviously not for me": Robots, laboratories and the defiant identity of elder test users. Sociology of Health and Illness, 32(2), 335-347 
[61] Pino, M., Boulay, M., Jouen, F., \& Rigaud, A. S. (2015) "Are we ready for robots that care for us?" Attitudes and opinions of older adults toward socially assistive robots. Frontiers in aging neuroscience, 7,141

[62] Kramer, M., Yaghoubzadeh, R., Kopp, S., \& Pitsch, K. (2013) A conversational virtual human as autonomous assistant for elderly and cognitively impaired users? Social acceptability and design considerations. Lecture Notes in Informatics (LNI), P-220, 1119

[63] Garner, T. A., Powell, W. A., and Carr, V. (2016) DIGITAL Virtual carers for the elderly: A case study review of ethical responsibilities. Digital Health, 2, 1-14

[64] Beer, J. M., Smarr, C. A., Chen, T. L., Prakash, A., Mitzner, T. L., Kemp, C. C., and Rogers, W. A. (2012 March) The domesticated robot: design guidelines for assisting older adults to age in place. In Proceedings of the seventh annual ACM/IEEE international conference on Human-Robot Interaction, Boston, MA, USA, 2012 (pp. 335-342)

[65] Draper, H., Sorell, T., Ruiz, S. B .C. G., Lehmann, H., Hervé, M., Gelderblom, G. J., Dautenhahn, K., and Amirabdollahian, F. (2014) What asking potential users about ethical values adds to our understanding of an ethical framework for social robots for older people. Paper presented at AISB50 - 50 ${ }^{\text {th }}$ Annual Convention of the AISB, London, United Kingdom

[66] Sharkey, A., and Sharkey, N. (2012) Granny and the robots: ethical issues in robot care for the elderly. Ethics and Information Technology, 14(1), 2740

[67] Wu, Y. H., Cristancho-Lacroix, V., Fassert, C., Faucounau, V., De Rotrou, J., and Rigaud, A. S. (2016) The attitudes and perceptions of older adults with mild cognitive impairment toward an assistive robot. Journal of Applied Gerontology, 35(1), 3-17

[68] Hutson, S., Lim, S. L., Bentley, P. J., Bianchi-Berthouze, N., and Bowling, A. (2011 October) Investigating the suitability of social robots for the wellbeing of the elderly. In International Conference on Affective Computing and Intelligent Interaction, Berlin, Heidelberg: Springer (pp. 578-587)

[69] Vardoulakis, L. P., Ring, L., Barry, B., Sidner, C. L., \& Bickmore, T. (2012 September) Designing relational agents as long term social companions for older adults. In International Conference on Intelligent Virtual Agents, Berlin, Heidelberg: Springer (pp. 289-302)

[70] Wu, Y. H., Fassert, C., and Rigaud, A. S. (2012) Designing robots for the elderly: appearance issue and beyond. Archives of Gerontology and Geriatrics, 54(1), 121-126

[71] Fischinger, D., Einramhof, P., Papoutsakis, K., Wohlkinger, W., Mayer, P., Panek, P., Hofmann, S., Koertner, T., Weiss, A., Argyros, A., and Vincze, 
M. (2016) Hobbit, a care robot supporting independent living at home: First prototype and lessons learned. Robotics and Autonomous System, 75, 6078

[72] Smarr, C. A., Prakash, A., Beer, J. M., Mitzner, T. L., Kemp, C. C., and Rogers, W. A. (2012 September) Older adults' preferences for and acceptance of robot assistance for everyday living tasks. In Proceedings of the human factors and ergonomics society annual meeting, Los Angeles, CA: SAGE Publications (Vol. 56, No. 1, pp. 153-157)

[73] Smarr, C. A., Mitzner, T. L., Beer, J. M., Prakash, A., Chen, T. L., Kemp, C. C., and Rogers, W. A. (2014) Domestic Robots for Older Adults: Attitudes, Preferences, and Potential. International Journal of Social Robotics, 6(2), 229-247

[74] Meng, Q., and Lee, M. H. (2006) Design issues for assistive robotics for the elderly. Advanced Engineering Informatics, 20, 171-186

[75] Olsson, T. (2014) Layers of user expectations of future technologies: an early framework. CHI'14 Extended Abstracts on Human Factors in Computing Systems (pp. 1957-1962)

[76] Shaked, N. A. (2017) Avatars and virtual agents - relationship interfaces for the elderly. Healthcare Technology Letters, 4(3), 83-87

[77] Koceski, S., \& Koceska, N. (2016) Evaluation of an assistive telepresence robot for elderly healthcare. Journal of Medical Systems, 40(5), 1-7

[78] Louie, W. Y., McColl, D., and Nejat, G. (2014) Acceptance and attitudes toward a human-like socially assistive robot by older adults. Assistive Technology 26(3), 140-50

[79] Libin, A. V., and Libin, E. V. (2003) New diagnostic tool for robotic psychology and robotherapy studies. Cyberpsychology and Behavior 6,(4), 369-374)

[80] Libin, A. V., and Libin, E. V. (2004) Person-robot interactions from the robopsychologists' point of view: The robotic psychology and robotherapy approach. Proceedings of the IEEE, 92(11) (pp. 1789-1803)

[81] Broadbent, E., Tamagawa, R., Patience, A., Knock, B., Kerse, N., Day, K., and MacDonald, B. A. (2012) Attitudes towards health-care robots in a retirement village. Australasian Journal on Ageing, 31(2), 115-120

[82] Nomura, T., Suzuki, T., Kanda, T., \& Kato, K. (2006) Measurement of negative attitudes toward robots. Interaction Studies, 7(3), 437-454

[83] Nomura, T., Kanda, T., Suzuki, T., and Kato, K. (2008) Prediction of human behavior in human-robot interaction using psychological scales for anxiety and negative attitudes toward robots. IEEE Transactions on Robotics, 24(2), pp. 442-451 
[84] Nomura, T., Suzuki, T., Kanda, T., \& Kato, K. (2006 September). Measurement of anxiety toward robots. In ROMAN 2006 - The $15^{\text {th }}$ IEEE International Symposium on Robot and Human Interactive Communication (pp. 372-377)

[85] Kamide, H., Takubo, T., Ohara, K., Mae, Y., and Arai, T. (2014) Impressions of humanoids: The development of a measure for evaluating a humanoid. International Journal of Social Robotics, 6, 33-44

[86] Bartneck, C., Kuli' c, D., Croft, E., and Zoghbi, S. (2009) Measurement instruments for the anthropomorphism, animacy, likeability, perceived intelligence, and perceived safety of robots. International Journal of Social Robotics, 1(1), 71-81

[87] Zasloff, R. L. (1996) Measuring attachment to companion animals: A dog is not a cat is not a bird. Applied Animal Behaviour Science, 47(1-2), 43-48

[88] Orejana, J. R., MacDonald, B. A., Ahn, H. S., Peri, K., and Broadbent, E. (2015 October) Healthcare robots in homes of rural older adults. In International Conference on Social Robotics, Springer, Cham, 2015 (pp. 512-521)

[89] Johnson, T. P., Garrity, T. F., and Stallones, L. (1992) Psychometric evaluation of the Lexington Attachment to Pets scale (LAPS) Anthrozoos, $5,160-175$

[90] Banks, M. R., Willoughby, L. M., and Banks, W. A. (2008) Animalassisted therapy and loneliness in nursing homes: Use of robotic versus living dogs. Journal of the American Medical Directors Association, 9(3), 173-177

[91] Poresky, R. H., Hendrix, C., Mosier, J. E., and Samuelson, M. L. (1987) The companion animal bonding scale: Internal reliability and construct validity. Psychological Reports, 60(3), 743-746

[92] Fasola, J., and Mataric, M. J. (2012) Using socially assistive human-robot interaction to motivate physical exercise for older adults. Proceedings of the IEEE, 100(8), pp. 2512-2526

[93] Bickmore, T. W., Caruso, L., and Clough-Gorr, K. (2005 April) Acceptance and usability of a relational agent interface by urban older adults. In CHI'05 extended abstracts on human factors in computing systems, Portland, Oregon, USA, 2005 (pp. 1212-1215)

[94] Horvath, A., and Greenberg, L. (1989) Development and validation of the working alliance inventory. Journal of Counseling Psychology 36, 223-233

[95] Bickmore, T. W., and Picard, R. W. (2005) Establishing and maintaining long-term human-computer relationships. ACM Transactions on Computer-Human Interaction (TOCHI) 12(2), 293-327 
[96] Watson, D., Clark, L. A., and Tellegen A. (1988) Development and validation of brief measures of positive and negative affect: The positive and negative affect scales. Journal of Personality and Social Psychology, 54:1063-1070

[97] Berry, D. S., and Hansen, J. S. (1996) Positive affect, negative affect, and social interaction. Journal of Personality and Social Psychology, 71(4), 796

[98] Ickes, W., Bissonnette, V., Garcia, S., Stinson, L. L. (1990) Implementing and using the dyadic interaction paradigm. In Hendrick C., Clark M.S., editors, Research methods in personality and social psychology. Thousand Oaks, CA: Sage (pp. 16-44)

[99] Broadbent, E., MacDonald, B., Jago, L., Juergens, M., and Mazharullah, O. (2007 October) Human reactions to good and bad robots. In IEEE/RSJ International Conference on Intelligent Robots and Systems, IROS, San Diego, CA, USA, 2007 (pp. 3703-3708)

[100] Bickmore, T., and Schulman, D. (2009 May) A virtual laboratory for studying long-term relationships between humans and virtual agents. In Proceedings of the 8th International Conference on Autonomous Agents and Multiagent Systems, Budapest, Hungary, 2009 (Vol. 1, pp. 297-304)

[101] Bickmore, T. W., Silliman, R. A., Nelson, K., Cheng, D. M., Winter, M., Henault, L., and Paasche-Orlow, M. K. (2013) A randomized controlled trial of an automated exercise coach for older adults. Journal of the American Geriatrics Society, 61(10), 1676-1683

[102] Cavallo F, Limosani R, Manzi A, Bonaccorsi M, Esposito R, Di Rocco M, et al. (2014) Development of a socially believable multi-robot solution from town to home. Cognitive Computation, 6(4), 954-967

[103] Cereghetti, D. M., Kleanthous, S., Christophorou, C., Tsiourti, C., Wings, C., and Christodoulou, E. (2015) Virtual partners for Seniors: Analysis of the users' preferences and expectations on personality and appearance. In Proceedings of the European Conference on Ambient Intelligence, Athens, 2015 (Vol. 1528, pp. 7-10)

[104] Groom, V., Nass, C., Chen, T., Nielsen, A., Scarborough, J. K., and Robles, E. (2009) Evaluating the effects of behavioral realism in embodied agents. International Journal of Human-Computer Studies, 67(10), 842-849

[105] Lee, M., Rittenhouse, M., and Abdullah, H. A. (2005) Design issues for therapeutic robot systems: results from a survey of physiotherapists. Journal of Intelligent and Robotic Systems, 42(3), 239-252

[106] Odetti, L., Anerdi, G., Barbieri, M. P., Mazzei, D., Rizza, E., Dario, P., ... and Micera, S. (2007 August) Preliminary experiments on the acceptability of animaloid companion robots by older people with early dementia. In $29^{\text {th }}$ Annual International Conference of the IEEE, EMBS, Cité Internationale, Lyon, France, 2007 (pp. 1816-1819) 
[107] Ring, L., Barry, B., Totzke, K., and Bickmore, T. (2013 September) Addressing loneliness and isolation in older adults: Proactive affective agents provide better support. In Humaine Association Conference on Affective Computing and Intelligent Interaction (ACII), Geneva, Switzerland, 2013 (pp. 61-66)

[108] Schneider, E., Wang, Y., and Yang, S. (2007 September) Exploring the Uncanny Valley with Japanese Video Game Characters. In DiGRA Conference, Tokio, Japan, 2007 (pp. 546-549)

[109] Seelye, A. M., Wild, K. V., Larimer, N., Maxwell, S., Kearns, P., and Kaye, J. A. (2012) Reactions to a remote-controlled video-communication robot in Seniors' homes: a pilot study of feasibility and acceptance. Telemedicine and e-Health, 18(10), 755-759

[110] Tapus, A., Tapus, C., and Mataric, M. (2009 September) The role of physical embodiment of a therapist robot for individuals with cognitive impairments. In the $18^{\text {th }}$ IEEE International Symposium on Robot and Human Interactive Communication, Toyama, Japan, RO-MAN, 2009 (pp. 103-107)

[111] Van Vugt, H. C., Konijn, E. A., Hoorn, J. F., and Veldhuis, J. (2006 August) Why fat interface characters are better e-health advisors. In International Workshop on Intelligent Virtual Agents, Berlin, Heidelberg: Springer, 2006 (pp. 1-13)

[112] Wada, K., Shibata, T., Musha, T., and Kimura, S. (2005 August) Effects of robot therapy for demented patients evaluated by EEG. In IEEE/RSJ International Conference on Intelligent Robots and Systems, Edmonton, Alta, Canada, 2005 (pp. 1552-1557)

[113] Wada, K., Shibata, T., Musha, T., and Kimura, S. (2008) Robot therapy for elders affected by dementia. In IEEE Engineering in Medicine and Biology Magazine, 27(4), 53-60

[114] Sharkey, A. (2014) Robots and human dignity: a consideration of the effects of robot care on the dignity of older people. Ethics and Information Technology, 16(1), 63-75

[115] Wilkowska, W., and Ziefle, M. (2012) Privacy and data security in Ehealth: Requirements from the user's perspective. Health informatics journal, 18(3), 191-201 